Mammal Study $23: 49-62$ (1998)

(C) the Mammalogical Society of Japan

\title{
Food habits of sympatric insectivorous bats in southern Kyushu, Japan
}

\author{
Kimitake FUNAKOSHI ${ }^{1}$ and Yuki TAKEDA ${ }^{2}$ \\ 'Biological Laboratory, Kagoshima Keizai University, Kagoshima 891-0191, Japan \\ Fax. +81-99-261-3299, e-mail. funakoshi@ soc.kkis.ac.jp \\ ${ }^{2}$ Department of Biology, Faculty of Science, Kagoshima University, Kagoshima 890-0065, \\ Japan \\ (Present address: Yakusugi Museum, Yaku-cho 891-4311, Japan)
}

\begin{abstract}
Five species of bats, Myotis nattereri, M. macrodactylus, Miniopterus fuliginosus, Rhinolophus ferrumequinum and $R$. cornutus were found to forage in the same habitats in southern Kyushu, Japan. M. nattereri fed mainly on Lepidoptera, Coleoptera, Diptera and Araneae, the proportions of each of these in the diet fluctuating seasonally, however, Lepidoptera and Coleoptera, especially, were consumed selectively. Their available prey items ranged in body length from 5-13 mm in length. $M$. macrodactylus preyed mainly on Diptera, Trichoptera and Lepidoptera, that were larger $(7-20 \mathrm{~mm})$ than those eaten by $M$. nattereri. Small or medium-sized Lepidoptera constituted the bulk of $M$. fuliginosus' diet in summer. $R$. ferrumequinum fed chiefly on larger Diptera, Coleoptera and Lepidoptera measuring 8-45 $\mathrm{mm}$ in body length, and clearly selected beetles despite these being relatively few in the trap samples. Lepidoptera and Diptera measuring 7-23 mm were important dietary components for $R$. cornutus, and despite their abundance being relatively low in summer moths were selectively preyed upon. These five bat species selectively hunted particular prey species in addition to taking food opportunistically. Through differences in both foraging-site and in prey selection, they seem to be able to coexist in the same habitat.
\end{abstract}

Key words: fecal analysis, food habits, insectivorous bats, prey selection, resource partitioning.

Food and roosts are potentially limiting resources that may affect the community structure of bats (Findley 1993), consequently, studies of foraging ecology and behavior may provide an insight into mechanisms that have permitted local coexistence in bat communities by reducing or eliminating competition (Kunz 1973). Information about prey selection and resource partitioning is very important for an understanding of how sympatric species of bats can coexist. Insectivorous bats are particularly interesting subjects for such studies because both the availability of insects to them is readily monitored and their actual diets can be determined by fecal analysis (Whitaker 1988).

Despite this, little is known about the resource partitioning or dietary overlap of sympatric insectivorous bat species (Black 1974, Swift and Racey 
1983, Hickey et al. 1996), and in fact relatively few studies have examined the relationship between the prey actually eaten by bats and the abundance of available insects (Black 1974, Funakoshi and Uchida 1975, 1978, Anthony and Kunz, 1977, Swift et al. 1985, Lacki et al. 1995). In Japan, there have been very few detailed studies of the food habits of insectivorous bats (Kuramoto 1972, Funakoshi and Uchida 1975, 1978).

Nothing was previously known of the food habits of either Myotis nattereri or $M$. macrodactylus in the field, thus here we report the first information on the dietary composition of these two species, and in addition we evaluate prey selection by M. nattereri, M. macrodactylus, Miniopterus fuliginosus, Rhinolophus ferrumequinum and $R$. cornutus in relation to food availability, and we examine whether resource partitioning occurs among these sympatric species.

\section{MATERIALS AND METHODS}

Principal investigations were made in and around the tuffaceous Katanodo Cave in Kagoshima Prefecture from the spring of 1994 to the fall of 1995. The vegetation of this region consists of secondary laurel forests and coppice forests, with fields on the western side and Cryptomeria japonica plantations to the south. A small brook flows near the entrance of the cave. M. nattereri, $M$. macrodactylus, M. fuliginosus, $R$. ferrumequinum and $R$. cornutus were all found at the cave from spring to fall (Funakoshi 1988, 1991). Bats were captured using either insect sweep nets or mist nets. Their sex and age were noted, and each bat was marked with a wing-band then released. We collected 30-50 fresh feces under the roosting sites of the colonies of each species in the cave and by placing captured bats into holding bags. Feces of $M$. nattereri and $R$. ferrumequinum in particular were collected every month to detect seasonal changes in their diets.

Insects were collected during the study period, using an insect suction trap (Tokyo AS Co. Ltd. Model DC-12) and a light trap with 20-watt white and black lights at $30 \mathrm{~min}$ intervals from dusk until dawn in the area where bats were foraging. Feces were collected occasionally from Obirano-dō and Nakadakedō Caves which are situated near Katano-dō Cave (Funakoshi 1988). The vegetation around all three caves is similar. M. nattereri, M. fuliginosus and $R$. ferrumequinum were found in Obirano-dō and Nakadake-dō Caves from spring to fall, and $M$. macrodactylus and $R$. cornutus were found there occasionally. Data from fecal samples at Katano-dō Cave were supplemented with samples from Obirano-dō and Nakadake-dō Caves.

Insects from the suction trap samples, were identified and the proportion of each insect order was determined. Several insects from each family caught at the light traps were crushed with forceps and keys were compiled from the fragments in order to assist in the identification of insect parts recovered from bat feces. All feces were examined under a binocular microscope. Recognizable fragments were extracted, and were identified with reference to the keys. The frequency of occurrence of each order of insects in fecal components was 
given as a ratio of the number of the feces including one or more fragments of a certain order of insects to the sum of the number of feces in which one or more fragments were found for each order.

\section{RESULTS}

\section{Seasonal changes in population size}

In spring, $M$. nattereri, $M$. macrodactylus, $M$. fuliginosus and $R$. ferrumequinum moved into Katano-dō Cave from their hibernaculae (Fig. 1). Before parturition in May and June, the $M$. nattereri and $M$. macrodactylus colonies consisted almost entirely of pregnant females $(80 \mathrm{M}$. nattereri, and $50 \mathrm{M}$. macrodactylus). By the weaning season, the number of $M$. nattereri had increased to 150 and $M$. macrodactylus to 80 . During late November, they emigrated. In summer, the $M$. fuliginosus colony consisted of 2,000-4,000 adult and subadult males, and subadult females (Fig. 1). During October that number diminished to about 1,000, and thereafter the remainder emigrated. In June, the colony of $R$. ferrumequinum consisted almost entirely of adult females, and their number was 150 (Fig. 1). During July, the lactating season, the colony attained its maximum size of 300 adult and subadult females, and young bats. A total of $120 R$. cornutus hibernated at Katano-dō Cave (Fig. 1). Their number diminished during April, increased by 40-80 in May-July, then decreased again during August-October. Most of them were adult and subadult

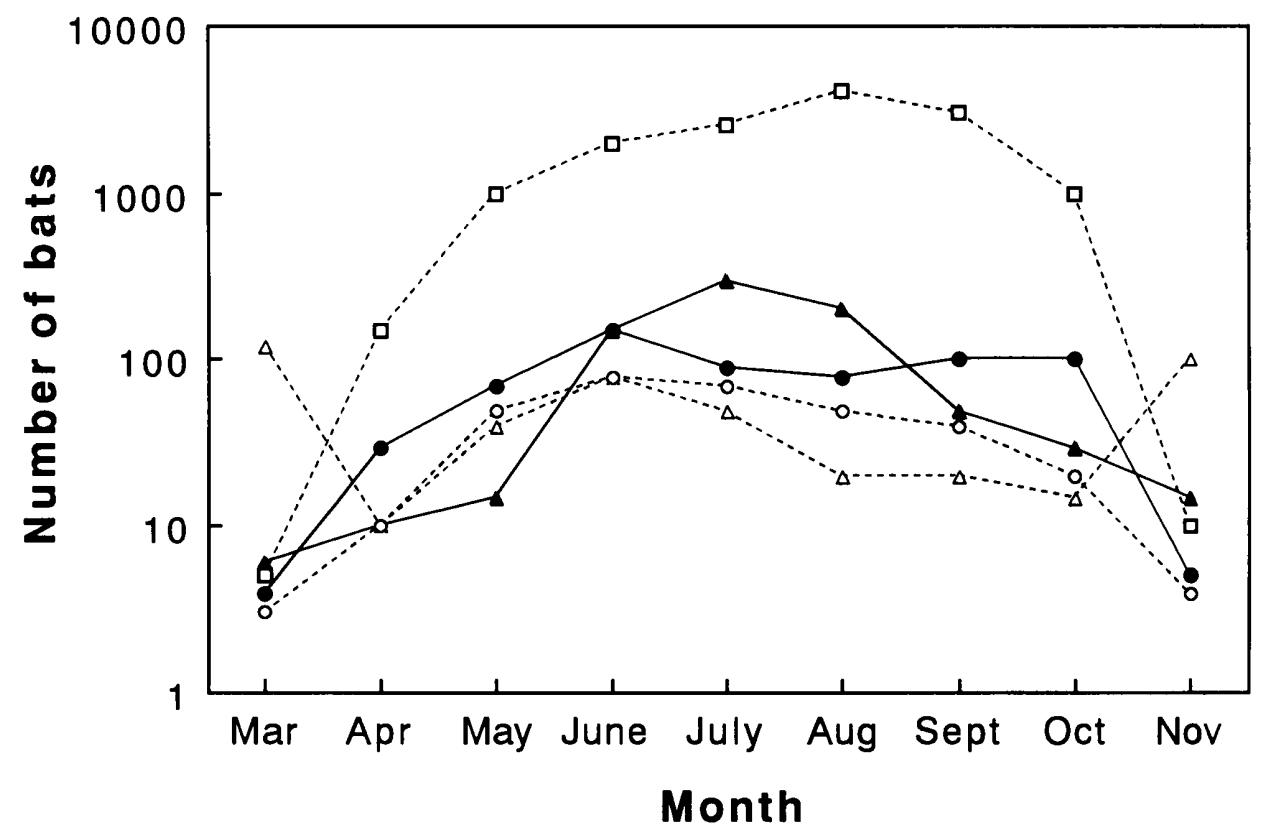

Fig. 1. Seasonal changes in the numbers of $R$. cornutus $(\cdots-\cdots), R$. ferrumequinum $(\longrightarrow$ ), M. macrodactylus ( $\cdots \bigcirc \cdots)$, M. nattereri $(-\longrightarrow)$ and M. fuliginosus $(\cdots \square \cdots)$ at Katano-dō Cave in 1994. 
males and subadult females.

\section{Food habits}

Five orders of volant insects: Diptera, Lepidoptera, Coleoptera, Trichoptera and Ephemeroptera, as well as spiders (Araneae) were represented in the diet of $M$. nattereri (Fig. 2). The body lengths of the available prey were 5-13 $\mathrm{mm}$ (Table 1). Among the taxa commonly preyed on by $M$. nattereri were Sericania (Scarabaeidae, body length ca. $11 \mathrm{~mm}$ ), Macrolagria rufobrunnea (Lagriidae, ca. $10 \mathrm{~mm}$ ), Carabidae (ca. $10 \mathrm{~mm})$, Tipulidae $(8-13 \mathrm{~mm})$, Araneidae (6-8 $\mathrm{mm})$, Tetragnatha (Tetragnathidae, 8-10 $\mathrm{mm}$ ) and Theridiidae (ca. $6 \mathrm{~mm})$. The frequency of the occurrence of Diptera in $M$. nattereri feces fluctuated between 15 and 39\% from April to November (see Fig. 2). The frequency of Lepidoptera was 15-26\% from April to August, but increased to $33-50 \%$ in fall. The frequency of Coleoptera was $42 \%$ in April, but dropped to $8 \%$ in May before increasing to $18-27 \%$ in summer, and then falling to $7-21 \%$ in fall. The occurrence of Trichoptera and Ephemeroptera was less than 13\% from April to November, while the Araneae varied from 3-48\% from April to November, peaking $40-48 \%$ in May-June.

The prey of $R$. ferrumequinum included Diptera, Lepidoptera, Coleoptera, Trichoptera and Plecoptera (Fig. 3), ranging in size from 8 to $45 \mathrm{~mm}$ (Table 1). Species or genera that were frequently found in the diet included: Tipula coquilletti, other Tipulidae and Tabanus (Diptera, 14-30 mm in body length); Holotrichia picea, Anomala cuprea, A. geniculata, A. daimiana, A. albopilosa, Melolontha japonica, M. satsumaensis, Mimela splendens, M. costata, Maladera castanea, M. secreta, Hydaticus grammicus, Melanotus legatus and Prionus insularis (Coleoptera, 10-45 mm long). The frequency occurrence of Diptera

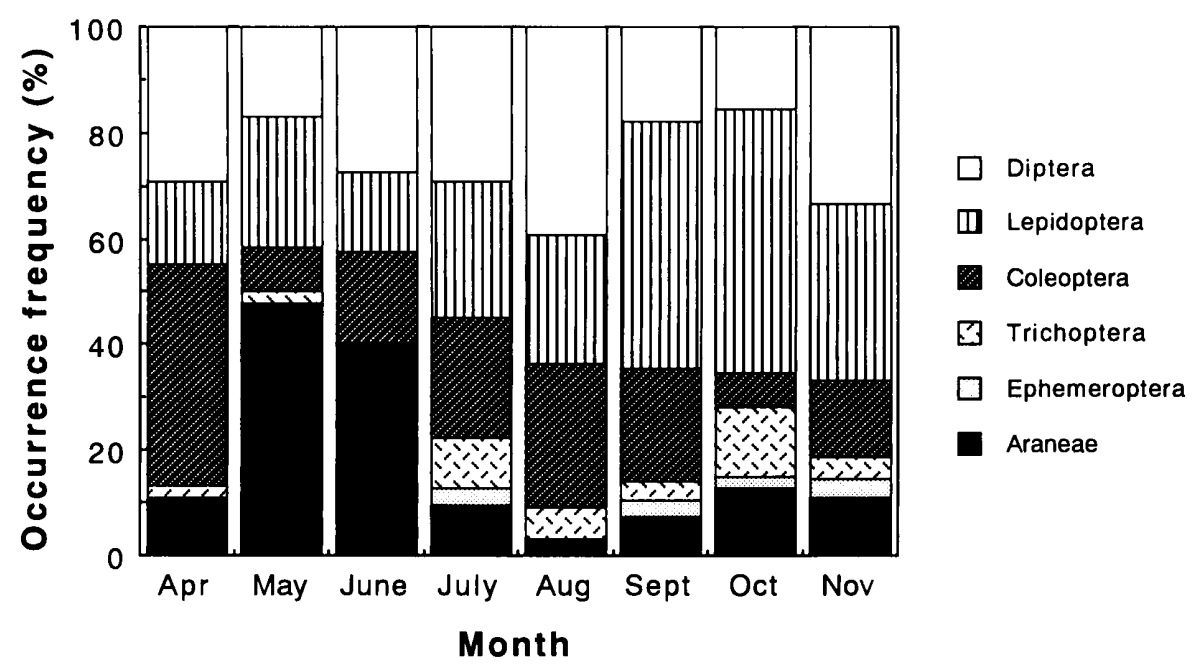

Fig. 2. Seasonal changes in occurrence frequency of foods (order level of insects) in the feces of M. nattereri in 1994-1995. 
Table 1. Body length for each order of insects found in fecal pellets of bats.

\begin{tabular}{llc}
\hline \multicolumn{1}{c}{ Bat species } & Prey item & $\begin{array}{c}\text { Body length } \\
(\mathrm{mm})\end{array}$ \\
\hline Myotis nattereri & Coleoptera & $6-12$ \\
& Lepidoptera & $8-13$ \\
& Diptera & $5-11$ \\
& Trichoptera & $8-10$ \\
& Ephemeroptera & $7-12$ \\
Myotis macrodactylus & Coleoptera & $8-18$ \\
& Lepidoptera & $7-15$ \\
& Diptera & $8-20$ \\
& Trichoptera & $8-11$ \\
& Ephemeroptera & $9-12$ \\
& Coleoptera & $6-15$ \\
& Lepidoptera & $6-25$ \\
& Diptera & $7-22$ \\
& Trichoptera & $5-10$ \\
& Ephemeroptera & $10-12$ \\
& Coleoptera & $8-22$ \\
& Lepidoptera & $9-23$ \\
& Diptera & $7-23$ \\
Rhinolophus cornutus & Trichoptera & $8-10$ \\
& Coleoptera & $9-45$ \\
& Lepidoptera & $12-27$ \\
& Diptera & $10-30$ \\
& Trichoptera & $8-12$ \\
\hline & & \\
& & \\
& &
\end{tabular}

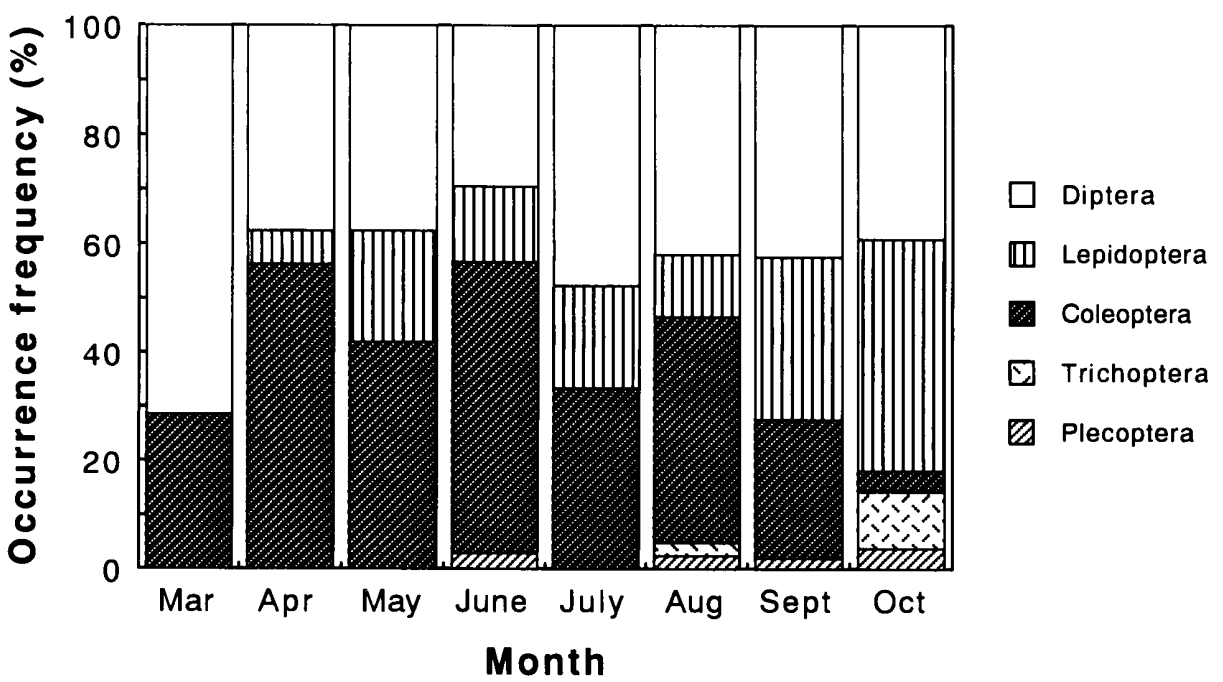

Fig. 3. Seasonal changes in occurrence frequency of foods (order level of insects) in the feces of $R$. ferrumequinum in 1994-1995. 
in $R$. ferrumequinum feces was $71 \%$ during March, but fluctuated between 30 and $48 \%$ from April to October (Fig. 3). The frequency of Coleoptera in the diet varied between 26 and $56 \%$ from March to September, and dropped to $4 \%$ in October, whereas the frequency of Lepidoptera gradually increased from April onwards reaching $43 \%$ in October. The frequency occurrence of both Trichoptera and Plecoptera was less than 11\% from spring to fall. Most significant was that the combined frequency occurrence of both Diptera and Coleoptera was $80 \%$ or more from May to August.

The diet of $M$. macrodactylus included Diptera, Lepidoptera, Coleoptera, Trichoptera, Plecoptera, Ephemeroptera and Araneae, ranging in size from 7 to $20 \mathrm{~mm}$ in body length (Table 1). These bats commonly took for example: Tipulidae (8-20 mm in body length), Tabanidae (ca. $18 \mathrm{~mm})$, Scarabaeidae $(A$. geniculata ca. $12 \mathrm{~mm}, A$. daimiana ca. $16 \mathrm{~mm}$, and $H$. picea ca. $18 \mathrm{~mm}$ ), and Araneidae (ca. $10 \mathrm{~mm}$ ). The frequency occurrence of various prey from March to May as determined by analysis of $M$. macrodactylus feces were: Diptera $45 \%$, Trichoptera $18 \%$, Coleoptera $9 \%$, Plecoptera $9 \%$, Ephemeroptera $9 \%$, Lepidoptera $5 \%$ and Araneae $5 \%$. In July these frequencies changed to: Diptera $36 \%$, Trichoptera $16 \%$, Coleoptera $16 \%$, Lepidoptera $24 \%$ and Araneae $8 \%$ (Fig. 4).

The prey of $M$. fuliginosus in July, as measured by fecal analysis, included Diptera $23 \%$, Lepidoptera $44 \%$, Coleoptera $7 \%$, Trichoptera $14 \%$, Ephemeroptera $7 \%$ and Plecoptera $5 \%$ (Fig. 4), ranging in size from 5 to $25 \mathrm{~mm}$ in body length (Table 1). For example, the Tipulidae (Diptera) that were eaten measured, ca.10 $\mathrm{mm}$ and $A$. geniculata (Coleoptera) ca. $12 \mathrm{~mm}$.

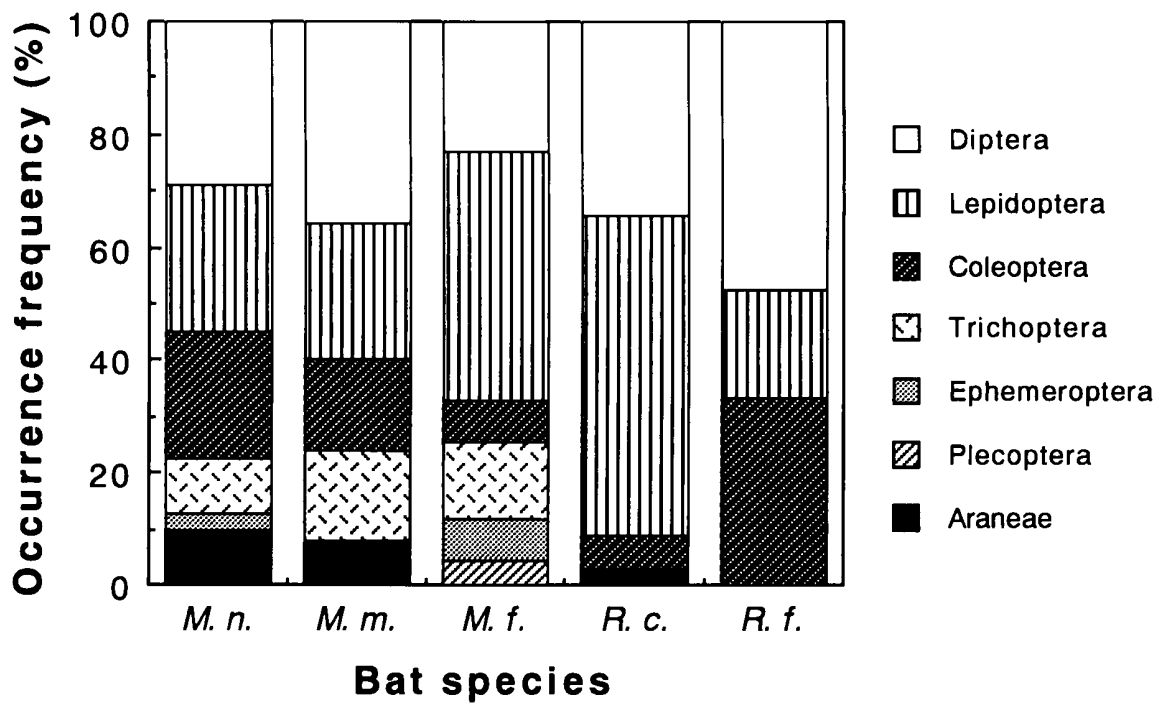

Fig. 4. Occurrence frequency of foods (order level of insects) in the feces of $M$. nattereri $(M$. $n$.), M. macrodactylus $(M . m$.), M. fuliginosus $(M . f),$.$R . cornutus (R . c$.) and $R$. ferrumequinum $(R . f$.$) in July of 1994$. 


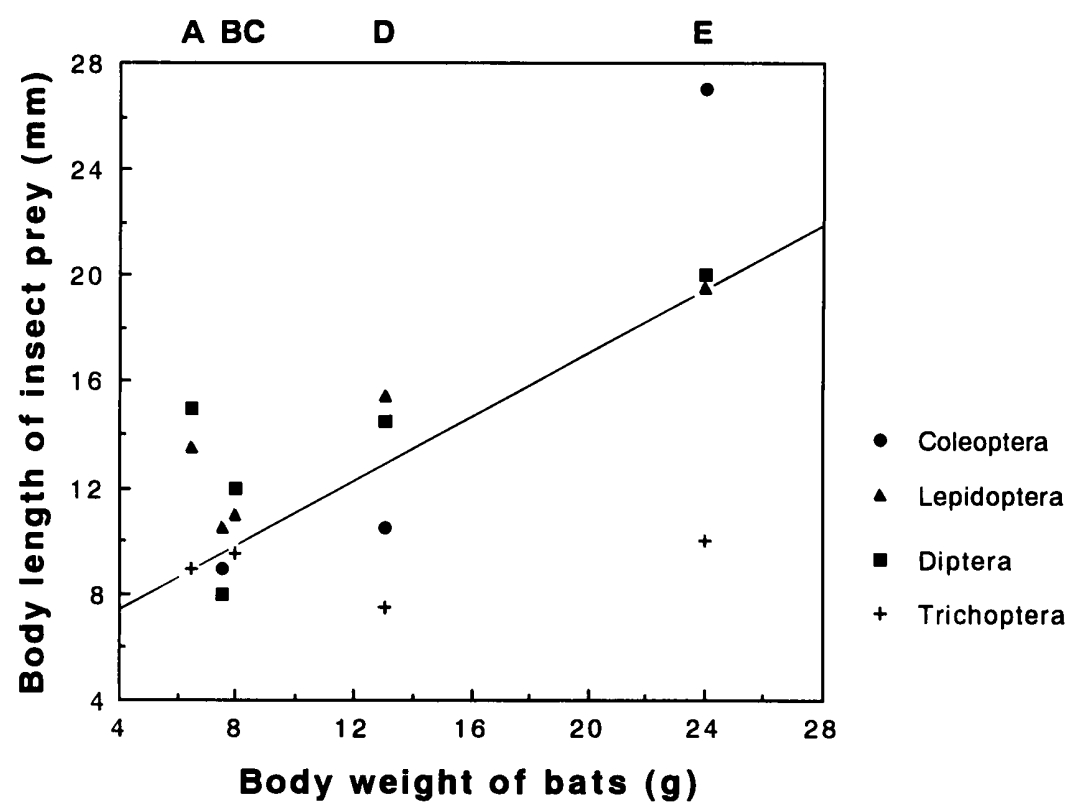

Fig. 5. Correlation of mean body weight of bats and mean body length of insect prey. A : $R$. cornutus, B: M. nattereri, C: M. macrodactylus, D : M. fuliginosus, E : R. ferrumequinum.

The diet of $R$. cornutus in July included Diptera $34 \%$, Lepidoptera $57 \%$, Coleoptera $6 \%$ and Araneae $3 \%$ (Fig. 4), ranging in size from 7 to $23 \mathrm{~mm}$ in body length (Table 1). In addition to these orders, Trichoptera was found in their feces in June. Typical examples were Tipulidae (Diptera) measuring 8$23 \mathrm{~mm}$, and M. castanea, A. geniculata and H. grammicus (Coleoptera), measuring $9-15 \mathrm{~mm}$.

A significant positive relationship was found between the mean body weight of the bats and the body length of their insect prey (Pearson's correlation coefficient : $r=0.63, p<0.01$, see Fig. 5).

\section{Insect abundance}

Total insect numbers (collected at the night) reached a peak during July, whereas dry weights were heaviest during June (see Figs. 6 and 7). In every month Diptera constituted a major portion of these samples (Fig. 6), but the ratio of the dry weight of Diptera to that of all insects trapped from April to September was less than $25 \%$ (Fig. 7). Trichoptera (4-25\%) and Ephemeroptera (1-21\%) were the next most abundant groups from April to November (Fig. 6), although the ratios of their dry weight to those of all insects was less than $16 \%$ for the Trichoptera, and less than $10 \%$ for the Ephemeroptera (Fig. 7). Lepidoptera and Coleoptera were often collected, but constituted only a small percentage of the total fauna (Fig. 6), yet the two orders contributed a 


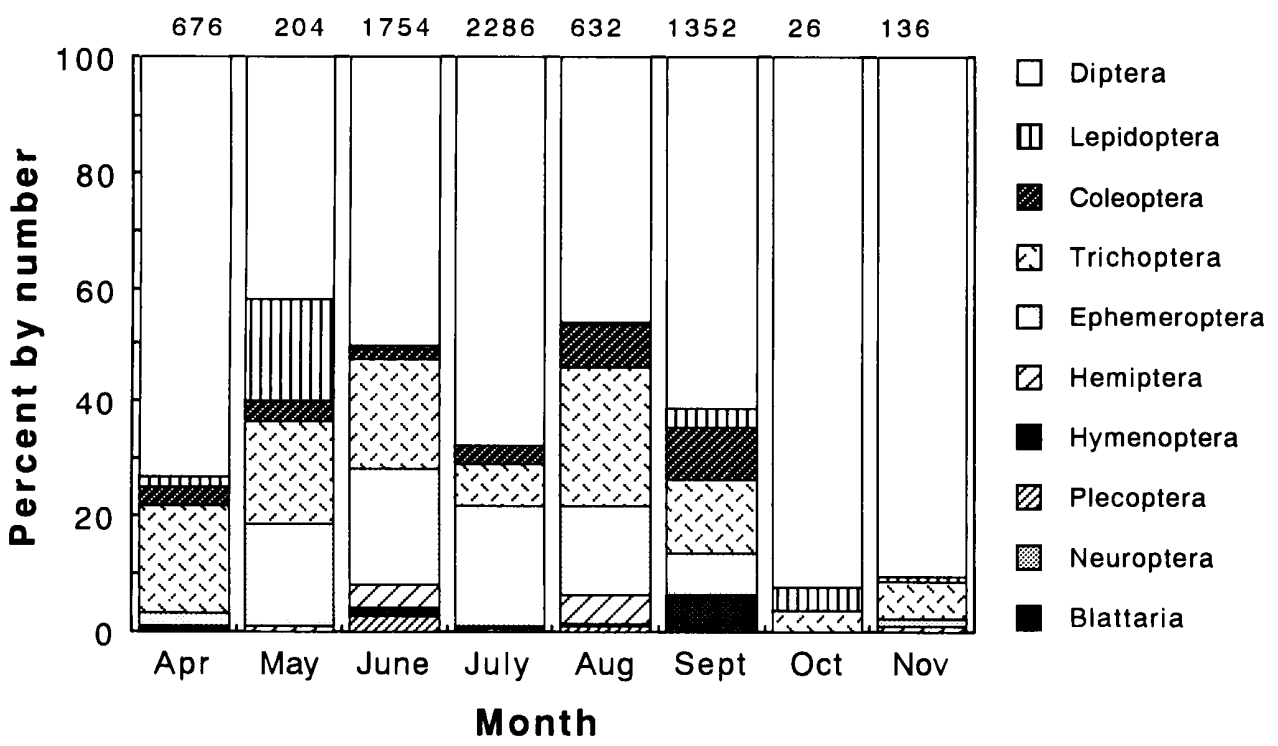

Fig. 6. Seasonal changes in percent number of insects of various orders collected by insect suction traps near Katano-dō Cave in 1994. Monthly sample sizes are indicated above histograms.

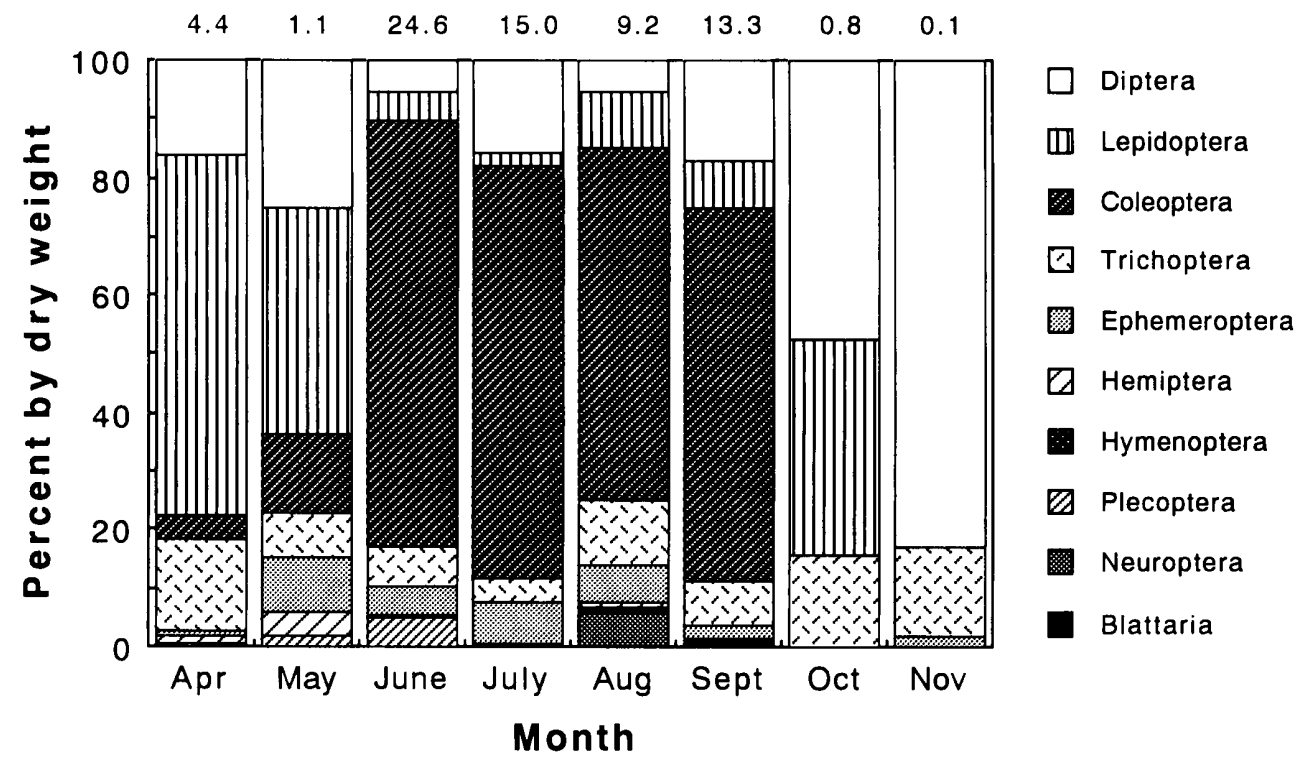

Fig. 7. Seasonal changes in percent dry weight of insects of various orders collected by insect suction traps near Katano-dō Cave in 1994. Monthly total dry weights (g) are indicated above histograms. 


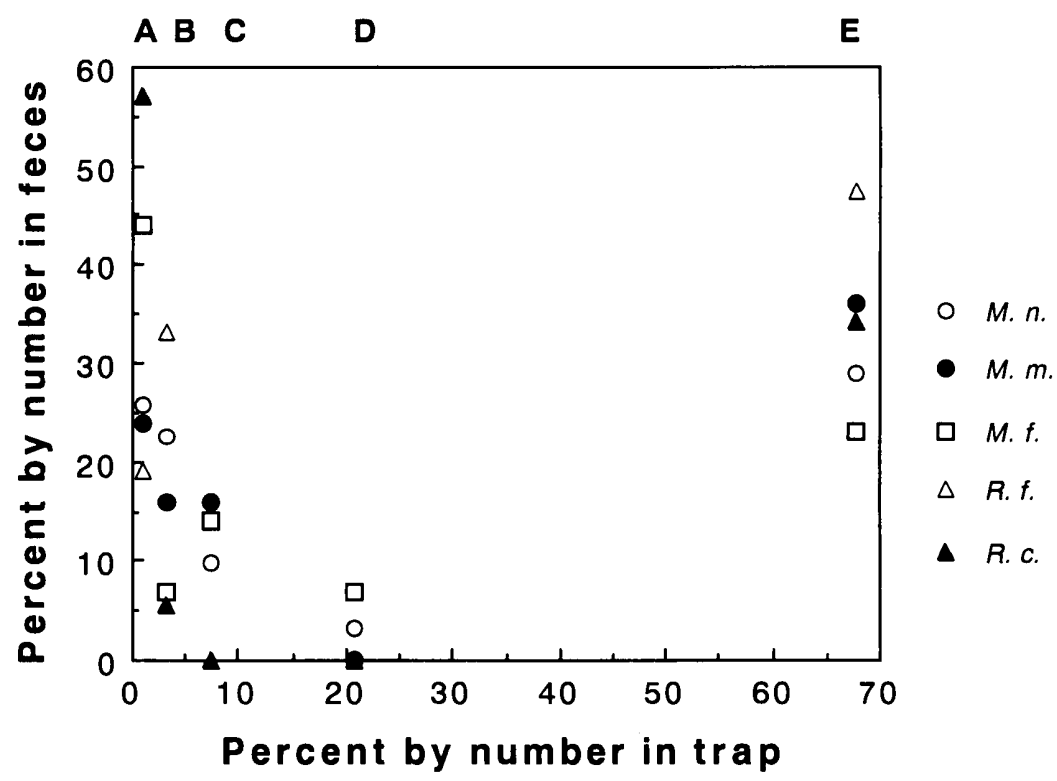

Fig. 8. Percent representation of each of five groups of insects in the feces of bats and in insect suction traps. A : Lepidoptera, B : Coleoptera, C: Trichoptera, D : Ephemeroptera, E: Diptera; M. n.: M. nattereri, M. m.: M. macrodactylus, M. $f .: M$. fuliginosus, $R . f .: R$. ferrumequinum, R. c.: R. cornutus.

high proportion of the dry weight. The ratio of the dry weight of Lepidoptera to that of all insects varied from 2 to $61 \%$ from April to October, being particularly high (37-61 \%) during April, May and October (Fig. 7). The ratio of dry weight of Coleoptera to that of all insects fluctuated even more widely between 4 and $73 \%$ from April to September, being particularly high (60-73\%) from June to September (Fig. 7).

When the rates of occurrence in bat feces of the five main insect groups were compared with the same groups occurring in traps during July, no correlation was found between the two values (Pearson's correlation coefficient : $r=$ $0.30, p>0.1$, see Fig. 8). The percentages of Diptera in the feces of both $M$. nattereri and $R$. ferrumequinum were significantly lower than those in the trap samples (Tables 2 and 3), whereas the percentages of Lepidoptera or Coleoptera in the feces were significantly larger.

In addition, spiders including Araneidae, Tetragnathidae and Theridiidae were frequently found along the edges of woodlands or brooks during May and June, however quantitative samples were not collected.

\section{Discussion}

\section{Prey selection}

M. nattereri was found to feed mainly on Lepidoptera, Coleoptera, Diptera 
Table 2. Proportions of five insect groups in insect suction traps and in the feces of $M$. nattereri for eight nights. Probability $(p)$ refers to Wilcoxon signed-ranks tests applied to establish whether each insect group was consistently commoner or rarer in the trap samples than in the fecal ones.

\begin{tabular}{lrrr}
\hline \multicolumn{1}{c}{ Order } & $\begin{array}{r}\text { \% trapped } \\
\text { Mean } \pm S D\end{array}$ & $\begin{array}{r}\text { \% in feces } \\
\text { Mean } \pm S D\end{array}$ & $p$ \\
\hline Diptera & $65.4 \pm 19.2$ & $32.1 \pm 9.8$ & $<0.01$ \\
Lepidoptera & $3.5 \pm 5.9$ & $36.2 \pm 14.4$ & $<0.01$ \\
Coleoptera & $3.4 \pm 3.3$ & $24.1 \pm 11.9$ & $<0.01$ \\
Trichoptera & $13.9 \pm 7.4$ & $5.8 \pm 4.8$ & N.S. \\
Ephemeroptera & $10.7 \pm 8.9$ & $1.8 \pm 1.9$ & N.S. \\
\hline
\end{tabular}

N. S. : not significant.

and Araneae, whereas aquatic insects such as Trichoptera and Ephemeroptera contributed smaller proportions of their diet. Lepidoptera and Coleoptera, in particular, were consistently selected by $M$. nattereri (Fig. 2 ; Table 2). Their predatory habits were probably a direct consequence of their particular preference for foraging in woodlands rather than over or near water, and this in turn was presumably related to their wing structure, as woodland foraging $M$. nattereri has relatively broader wings than does its close relative $M$. macrodactylus (Kuramoto 1972, Funakoshi 1988). Similarly, Myotis auriculus and Plecotus auritus, both of which have long ears, also prey mainly upon moths and beetles (Husar 1976, Swift and Racey 1983). P. auritus has relatively broader wings and a lower aspect ratio making it more maneuverable than $M$. auriculus, which characteristics make it possible for it to fly and hover skillfully (Norberg 1970), and hence to forage in thickly wooded areas (Swift and Racey 1983).

Spiders (Araneae) are a particularly important component of $M$. nattereri's diet, especially during May and June (Fig. 2), and they have also been found to be eaten by Nycteris thebaica, $P$. auritus, Plecotus townsendii virginianus and

Table 3. Proportions of five insect groups in insect suction traps and in the feces of $R$. ferrumequinum for seven nights. Probability $(p)$ refers to Wilcoxon signed-ranks tests applied to establish whether each insect group was consistently commoner or rarer in the trap samples than in the fecal ones.

\begin{tabular}{lrrc}
\hline \multicolumn{1}{c}{ Order } & $\begin{array}{r}\text { \% trapped } \\
\text { Mean } \pm S D\end{array}$ & $\begin{array}{r}\text { \% in feces } \\
\text { Mean } \pm S D\end{array}$ & $p$ \\
\hline Diptera & $61.8 \pm 17.6$ & $39.4 \pm 5.6$ & $<0.01$ \\
Lepidoptera & $3.9 \pm 6.2$ & $20.6 \pm 12.4$ & $<0.01$ \\
Coleoptera & $3.9 \pm 3.2$ & $36.6 \pm 18.1$ & $<0.01$ \\
Trichoptera & $15.0 \pm 7.3$ & $1.9 \pm 4.0$ & N.S. \\
Plecoptera & $0.5 \pm 0.9$ & $1.5 \pm 1.5$ & N.S. \\
\hline
\end{tabular}

N. S. : not significant. 
Myotis grisescens, although they contribute only very small percentages to their diets (LaVal and LaVal 1980, Swift and Racey 1983, Sample and Whitmore 1993, Best et al. 1997). Swift and Racey (1983) have even suggested that P. auritus may glean for spiders, however as some spiders were attached to gossamer they would also have been available to bats in full flight. In contrast, $M$. nattereri, $M$. macrodactylus and $R$. cornutus may catch spiders chiefly in flight, because nearly all of the spiders eaten were found to be snarers. It does seem that spiders may be consumed opportunistically by all these bats, when they were abundantly available.

In our study area $M$. nattereri foraged mainly in woodlands and ate smaller Lepidoptera, Coleoptera, Diptera and Araneae than other bats did (Table 1), whereas $M$. macrodactylus foraged not only in woodlands but also over or near water (Kuramoto 1972) and fed mainly on medium-sized Diptera, Trichoptera or Lepidoptera that were larger than those eaten by $M$. nattereri (Table 1). As a consequence of their preferred riparian foraging habitat, $M$. macrodactylus often fed on aquatic insects such as Trichoptera, Ephemeroptera and Plecoptera. Another species foraging very similarly is Myotis daubentoni, which flies almost entirely above water and riparian vegetation and feeds mainly on Diptera and Trichoptera (Swift and Racey 1983).

$M$. fuliginosus has relatively long-narrow wings and a high aspect ratio, enabling it to fly quickly (Kuramoto 1972). It prefers to forage above the woodland canopy or over water, where in summer it prefers small or mediumsized moths (Kuramoto 1972, Funakoshi and Uchida 1975; see Table 1, Figs 4 and 8). Other populations of this species in Kumamoto Prefecture, Kyushu, have also been shown to consume largely Lepidoptera (Funakoshi and Uchida 1975). During spring or fall, however, they also feed opportunistically on insects, particularly on Diptera Trichoptera and Ephemeroptera (Funakoshi and Uchida 1975).

$R$. ferrumequinum is a relatively large bat with short, broad wings, capable of making short low speed flights and even hovering, which prefers to forage not only near or in thick woodlands but also in open spaces over water or over grasslands. They may also pursue prey on the ground (Kuramoto 1972). They feed mainly on relatively large insects such as Diptera, Coleoptera and Lepidoptera (Kuramoto 1972, this paper), the proportions in the diet changing seasonally (see Fig. 3, and Jones 1990). Beetles in particular were selectively consumed from April to September in Japan, even though their numbers in the trap samples were small (Table 3, Fig. 8), whereas moths constitute a major portion of this species' diet throughout the summer in England (Jones 1990). These bats, thus, probably select prey by size rather than by order during periods of abundance, and they also may engage in opportunistic feeding at times depending on prey availability and abundance. Opportunistic feeding by bats allows effective exploitation of patchily distributed food resources and can lead to selective feeding (Fenton and Morris 1976).

$R$. cornutus also has short-broad wings, giving it a very low wing-loading and low aspect ratio which enable it to fly or hover slowly and to roll rapidly 
while foraging near or in thick woodland and in open spaces (Kuramoto 1972). Lepidoptera and Diptera were found to be the first and second most important dietary items for $R$. cornutus, however they took smaller prey than $R$. ferrumequinum did (Fig. 4, Table 1). Despite their relatively low abundance during July, $R$. cornutus fed selectively on moths (Figs 6,7 and 8 ).

\section{Resource partitioning}

Spatial partitioning, with $M$. fuliginosus hunting in open spaces far above the woodland canopy or over water, ensures that there is little or no competition for food resources with the other four sympatric species which forage within or around foliage and in the open spaces between trees. Intraspecific competition for food may exist, however, in $M$. fuliginosus because they occur at high densities (Fig. 1).

As previously mentioned, $M$. nattereri and $M$. macrodactylus forage in partially different habitats, and feed on different sized insects. Their different prey sizes probably reflect the differences in their body sizes, and these differences may weaken niche overlap or competition between these two closely related and sympatric species. Two other similar-sized bats, $P$. auritus and $M$. daubentoni, are also known to partition resources in space and to eat different types of prey (Swift and Racey 1983), and M. auriculus and M. evotis, which closely resemble each other, and which have similar food habits when occurring allopatrically, avoid competition for food when occurring sympatrically by $M$. evotis changing its food preferences (Husar 1976).

$R$. ferrumequinum and $R$. cornutus are morphologically similar, but the former is about three times larger than the latter. The two species were found to forage in similar places, but consumed insects from different orders and of different sizes, thus is little overlap in their diets (Kuramoto 1972, this study). Similarly, Lasiurus cinereus is about twice as large as L. borealis, and where their ranges overlap, the former primarily eats larger moths while the latter eats smaller moths (Acharya and Fenton 1992, Hickey et al. 1996). The study colony of $R$. cornutus was relatively small (Fig. 1), and its members fed mainly on Lepidoptera which were less common in the trap samples in our study area (Fig. 6). The low abundance of preferred prey may be correlated with the small population size in summer.

The foraging areas of $R$. ferrumequinum, $M$. nattereri and $M$. macrodactylus partially overlap, thus competition for foods is perhaps being avoided by the differences in the size of their prefered prey. In particular, the larger $R$. ferrumequinum tended to eat larger insects such as chafers and gadflies. Similarly, niche overlap partially occurs between $R$. cornutus and $M$. nattereri or $M$. macrodactylus, however $R$. cornutus tends to emerge after sunset about 30 min earlier than the other species (Kuramoto 1972, also this study). As the main emergence time of insect prey was found to be within a few hours after sunset (Funakoshi and Takeda unpublished), foraging during this period may be very important for them to consume insects efficiently. It is probable that resource partitioning between them may occur in the same foraging areas 
through differences in both their prey selection and in their temporal activity.

Acknowledgments: We thank Drs S. Yamane, M. Hotta and J. Miyamoto of Kagoshima University for their encouragement and valuable advice, and Drs $\mathrm{T}$. Iwai and T. Masumoto for their kind help in the identification of insects and spiders. We are also indebted to T. Nagata, S. Wakiyama, M. Kobayashi, T. Yamada and C. J. Tyers for their help in the field work, and to Dr. M. Brazil for critically reading and comments on the final manuscript. This work was supported in part by a grant from Kagoshima Keizai University.

\section{REFERENCES}

Acharya, L. and M. B. Fenton. 1992. Echolocation behaviour of vespertilionid bats (Lasiurus cinereus and Lasiurus borealis) attacking airborne targets including arctiid moths. Can. J.Zool. 70 : $1292-1298$.

Anthony, E. L. P. and T. H. Kunz. 1977. Feeding strategies of the little brown bat, Myotis lucifugus, in southern New Hampshire. Ecology 58:775-786.

Best, T. L., B. A. Milan, T. D. Haas, W. S. Cvilikas and L. R. Saidak. 1997. Variation in diet of the gray bats (Myotis grisescens). J. Mammal. 78:569-583.

Black, H. L. 1974. A north temperate bat community: structure and prey populations. J. Mammal. $55: 138-157$.

Fenton, M. B. and G. K. Morris. 1976. Opportunistic feeding by desert bats (Myotis spp.). Can. J. Zool. $54: 526-530$

Findley, J. S. 1993. Bats: a community perspective. Cambridge University Press, Cambridge, 167 $\mathrm{pp}$.

Funakoshi, K. 1988. Habitat selection and population dynamics during the active season in the Natterer's bat, Myotis nattereri bombinus. Regional Studies 16:137-147 (in Japanese with English abstract).

Funakoshi, K. 1991. Reproductive ecology and social dynamics in nursery colonies of the Natterer's bat, Myotis nattereri bombinus. J. Mammal. Soc. Japan 15:61-71.

Funakoshi, K. and T. A. Uchida. 1975. Studies on the physiological and ecological adaptation of temperate insectivorous bats. I. Feeding activities in the Japanese long-fingered bats, Miniopterus schreibersi fuliginosus. Jap. J. Ecol. 25 : 217-234 (in Japanese with English synopsis).

Funakoshi, K. and T. A. Uchida. 1978. Studies on the physiological and ecological adaptation of temperate insectivorous bats. III. Annual activity of the Japanese house-dwelling bat, Pipistrellus abramus. J. Fac. Agr. Kyushu Univ. 23: 95-115.

Hickey, M. B., L. Achrya and S. Pennington. 1996. Resource partitioning by two species of vespertilionid bats (Lasiurus cinereus and Lasiurus borealis) feeding around street lights. J. Mammal. $77: 325-334$.

Husar, S. L. 1976. Behavioral character displacement : evidence of food partitioning in insectivorous bats. J. Mammal. $57: 331-338$.

Jones, G. 1990. Prey selection by the greater horseshoe bat (Rhinolophus ferrumequinim) : optimal foraging by echolocation ? J. Anim. Ecol. 59:587-602.

Kunz, T. H. 1973. Resource utilization: temporal and spatial components of bat activity in central Iowa. J. Mammal. $54: 14-32$.

Kuramoto, T. 1972. Studies on bats at the Akiyoshi-dai Plateau, with special reference to the ecological and phylogenic aspects. Bull. Akiyoshi-dai Sci. Mus. 8:7-119 (in Japanese with English abstract).

Lacki, M. J., L. S. Burford and J. O. Whitaker, Jr. 1995. Food habits of grey bats in Kentucky. J. Mammal. 76 : 1256-1259. 
LaVal, R. K. and M. L. LaVal. 1980. Prey selection by the slit-faced bat Nycteris thebaica (Chiroptera : Nycteridae) in Natal, South Africa. Biotropica 12:241-246.

Norberg, U. M. 1970. Hovering flight of Plecotus auritus Linnaeus. Bijdr. Dierk. 40:62-66.

Sample, B. E. and R. C. Whitmore. 1993. Food habits of the endangered Virginia big-eared bat in West Virginia. J. Mammal. $74: 428-435$.

Swift, S. M. and P. A. Racey. 1983. Resource partitioning in two species of vespertilionid bats (Chiroptera) occupying the same roost. J. Zool., Lond. 200:249-259.

Swift, S. M., P. A. Racey and M. I. Avery. 1985. Feeding ecology of Pipistrellus pipistrellus (Chiroptera : Vespertilionidae) during pregnancy and lactation. II. Diet. J. Anim. Ecol. 54:217-225.

Whitaker, J. O., Jr. 1988. Food habits analysis of insectivorous bats. In (T. H. Kunz, ed.) Ecological and Behavioral Methods for the Study of Bats. pp. 171-189. Smithsonian Institution Press, Washington. 